\title{
Electrochemistry on Stretchable Nanocomposite Electrodes: Dependence on Strain
}

Lionel Lopez, ${ }^{\dagger}$ Yoonseob Kim, ${ }^{\dagger}$ Loic Jierry, ${ }^{\dagger, \S}$ Joseph Hemmerle, ${ }^{\|, \perp}$ Fouzia Boulmedais, ${ }^{*}, \dagger$ Pierre Schaaf, ${ }^{*}, \S, \|, \perp, \#, \nabla \odot$ Sergey Pronkin, ${ }^{\otimes}$ and Nicholas A. Kotov*, ${ }^{*} \neq(\mathbb{0}$

${ }^{\dagger}$ Université de Strasbourg, CNRS, Institut Charles Sadron UPR 22, 67034 Strasbourg, France

${ }^{\ddagger}$ Department of Chemical Engineering, University of Michigan, Ann Arbor, Michigan 48109-2136, United States

${ }^{\S}$ Université de Strasbourg, Ecole de Chimie, Polymères et Matériaux, 67087 Strasbourg, France

"Institut National de la Santé et de la Recherche Médicale, UMR-S 1121, "Biomatériaux et Bioingénierie”, 67087 Strasbourg, France

${ }^{\perp}$ Université de Strasbourg, Faculté de Chirurgie Dentaire, Fédération de Médecine Translationnelle de Strasbourg (FMTS), and Fédération des Matériaux et Nanoscience d'Alsace (FMNA), 67000 Strasbourg, France

${ }^{\#}$ University of Strasbourg Institute of Advanced Study, 67083 Strasbourg, France

${ }^{\nabla}$ International Center for Frontier Research in Chemistry, 67083 Strasbourg, France

${ }^{\otimes}$ Université de Strasbourg, CNRS, ICPEES UMR 7515, 67087 Strasbourg, France

Supporting Information

ABSTRACT: Stretchable nanocomposite conductors are essential for engineering of bio-inspired deformable electronics, human-machine interfaces, and energy storage devices. While the effect of strain on conductivity for stretchable conductors has been thoroughly investigated, the strain dependence of multiple other electrical-transport processes and parameters that determine the functionalities and biocompatibility of deformable electrodes has received virtually no attention. The constancy of electrochemical parameters at electrode-fluid interfaces such as redox potentials, impedances, and charge-transfer rate constants on strain is often tacitly assumed. However, it remains unknown whether these foundational assumptions actually hold true for deformable electrodes. Furthermore, it is also unknown whether the previously used charge-transport circuits describing electrochemical processes on rigid electrodes are applicable to deformable electrodes. Here, we investigate the validity of the strain invariability assumptions for an elastic composite electrode based on gold nanoparticles (AuNPs). A comprehensive model of electrode reactions that accurately describes electrochemical processes taking place on nanocomposite electrodes for ferro-/ferricyanide electrochemicals pair at different strains is developed. Unlike rigid gold electrodes, the model circuit for stretchable electrodes is comprised of two parallel impedance segments describing (a) diffusion and redox processes taking place on the open surface of the composite electrode and (b) redox processes that occur in nanopores. AuNPs forming the open-surface circuit support the redox process, whereas those forming the nanopores only increase the double-layer capacitance. The redox potential was found to be strain-independent for tensile deformations as high as $40 \%$. Other parameters, however, display strong strain dependence, exemplified by the $2-2.5$ and 27 times increases of active area of the open and nanopore surface area, respectively, after application of $40 \%$ strain. Gaining better understanding of the strain-dependent and -independent electrochemical parameters enables both fundamental and practical advances in technologies based on deformable electrodes.

KEYWORDS: stretchable materials, biomimetic electronics, reconfigurable electrodes, electrochemical sensors, implantable devices, self-assembly
$\mathrm{T}$

he potential and current signals measured in electrochemical experiments are the result of the interplay between a large number of electron- and ion-transport
Received: May 25, 2018

Accepted: July 17, 2018

Published: July 17, 2018 

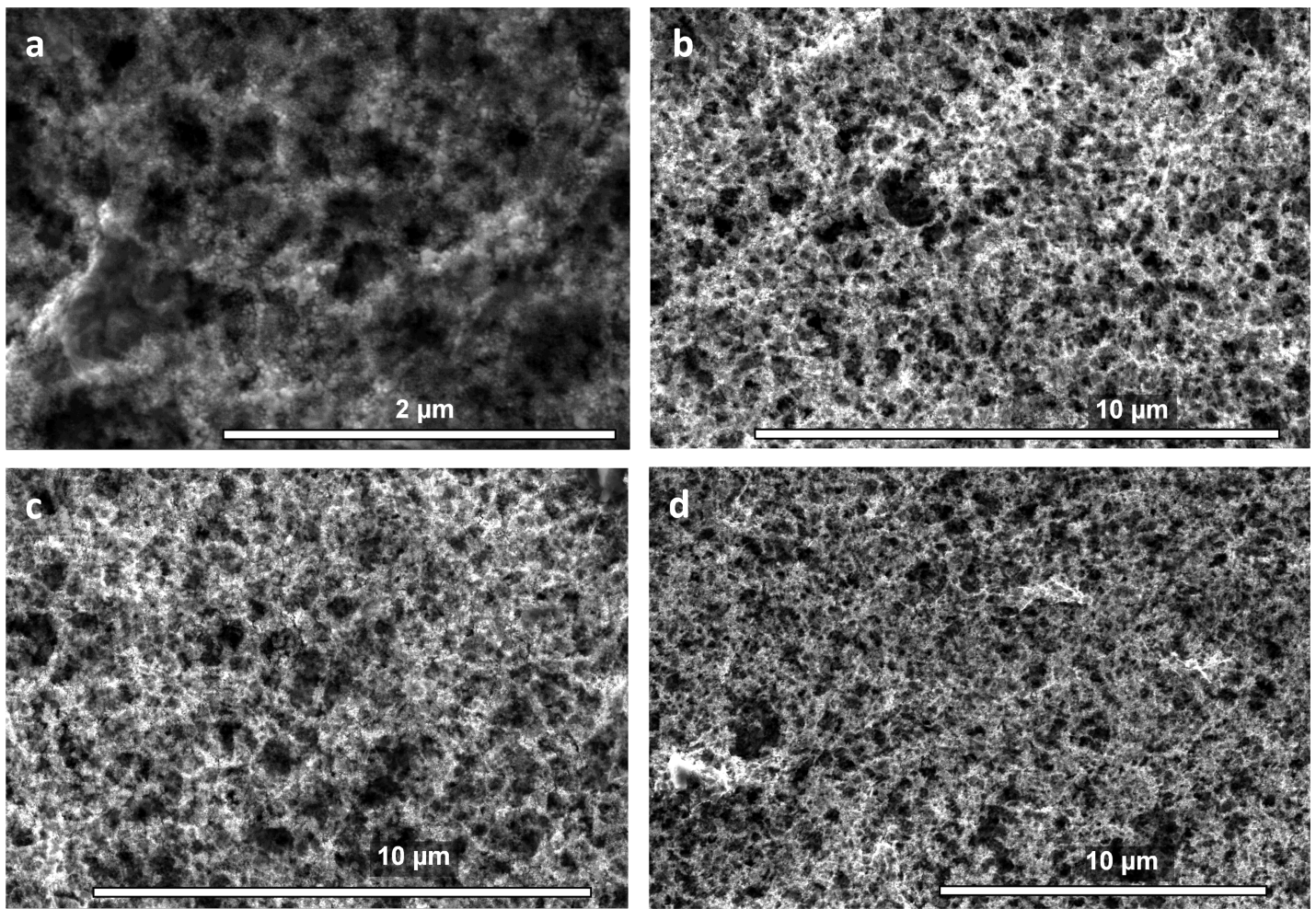

Figure 1. Scanning electron microscopy images of a composite Au/PU electrode (a,b) under $0 \%$ strain at different magnifications, and under (c) $20 \%$ and (d) $40 \%$ strain. No change in micron and submicron scale morphology is observed for these electrodes.

processes, including diffusion of different species toward and away from the electrode, charge transfer at the electrode, and surface interactions of electrolyte species. All of these processes are strongly dependent upon the electrode's chemistry, geometry, and topography. A large amount of research has been invested worldwide into the development of macro- and microelectrodes $^{1,2}$ and, more recently, stretchable electrodes. $^{3-9}$ The latter represent the key component of bio-inspired deformable electronics, ${ }^{7}$ human-machine interfaces, ${ }^{10}$ semipermanent wearable sensors, and safe energy storage devices. ${ }^{10}$ There are multiple studies that address the dependence of their conductivity on strain in nanocomposites. ${ }^{11-14}$ However, an analysis of the state-of-the-art in this field reveals how little we know about the strain dependence of other parameters that are critical for identifying the functionalities and biocompatibility of the deformable electrodes related to the electrochemistry at the surface of these stretchable electrodes. Understanding the dependence of the key electrochemical parameters such as redox potential, impedance, nanoscale porosity, and chargetransfer rate constants on strain is essential for all applications of deformable electrodes. Strain independence of electrochemistry at the interface of stretchable electrodes is often tacitly assumed, but experimental testing of this foundational assumption was never carried out. One should also expect that the electrochemical models for the electrode-electrolyte interface of the deformable composite electrode may be quite different than those for classical rigid electrodes due to nanoscale heterogeneity of these materials. Systematic studies deciphering the complexity of the electrochemical models for the deformable composite materials are needed for correct predictions of electrochemical responses of deformable electrodes.
Stretchable electrodes are produced from a variety of composite materials that "borrow" conductivity from nanomaterials and elasticity from polymers. Some materials design approaches include the deposition of wire-like nanoconductors onto elastomeric substrates to form conducting grids. ${ }^{15}$ Others involve incorporation of nanomaterials such as graphene, ${ }^{16}$ carbon black, ${ }^{17}$ metal nanowires, ${ }^{18}$ or nanoparticles $(\mathrm{NPs})^{14,19,20}$ into elastic polymers. The interface between the nanoscale conductive elements and electroactive fluid outside of the electrode changes upon strain for all of these nanocomposites, because the nanoscale objects adjust their mutual orientation (self-assemble) under strain. ${ }^{14,21-23}$ The focus of most studies in the past was the maximization of conductivity for large strains, ${ }^{24-28}$ although the conductivity of electrodes per se is a necessary but not the sufficient requirement for the realization of reliable human-machine interface, biosensor array, deformable energy storage, and other applications. One also needs to know of the strain dependence of electron-transport processes and the actual active surface area of the composite electrodes. The body of knowledge about such dependences is extremely limited. ${ }^{29-32}$ Nilchian and $\mathrm{Li}$ investigated strain dependence of electrodes made from carbon nanotubes incorporated into polydimethylsiloxane immersed into a solution of ferrocyanide/ferricyanide by electrochemical impedance spectroscopy (EIS) or cyclic voltammetry $(\mathrm{CV})$ for cyclic strains up to $300 \%{ }^{29} \mathrm{Kim}$ et al. investigated reduced graphene oxide/single-wall carbon nanotubes sprayed onto a gold-coated latex substrate ${ }^{30,31}$ for 100 stretching cycles at $100 \%$ strains. Wei et al. investigated the electrochemical behavior of a stretchable single-wall carbon nanotube electrode under compressive stress. ${ }^{32}$ Summarizing the outcome of these studies, the expectations of variable active area for electrodes and variable capacitive response were 
confirmed. However, the central questions of whether the electrochemistry of redox species varies with strain and whether classical circuit models are applicable to deformable electrodes remain open.

These questions are addressed in our study of the straindependent electrochemical processes for stretchable nanocomposites from gold described here. A stretchable conductor composed of cationic polyurethane and self-assembled AuNPs was obtained by using vacuum-assisted flocculation (VAF). This composite material exhibited conductivity of $104 \mathrm{~S} \cdot \mathrm{cm}^{-1}$ and could sustain greater than $100 \%$ strains without loss of conductance. EIS indicates that, in the relaxed state, the electrochemical behavior of the AuNP composite fits the model of a Randles circuit, but under strain, the nanoscale and molecular-scale porosity of electrodes changes dramatically. ${ }^{33}$ Depending on the nanoscale topography, AuNPs comprise two distinct subsets with dramatically different electrochemical activities: NP assemblies in the nanopores indistinguishable in the electron microscopy images and on the open surface. Such surface duality leads to fundamentally different mathematical models for the electrochemical behavior of deformable electrodes compared to the rigid metal electrodes.

\section{RESULTS AND DISCUSSION}

Structure of the Composite Electrodes. Before investigating the electrochemical properties of the $\mathrm{Au} / \mathrm{PU}$ nanocomposite electrode in its non-stretched and stretched states, we visualized it by scanning electron microscopy (SEM, Figure 1a,b). The Au/PU nanocomposite electrode displayed a surface with nanoscale roughness and pores that ranged in size from $\sim 300$ to $500 \mathrm{~nm}$. From the standpoint of electrochemistry, it is important that nanocomposite electrode did not display any significant change in its surface morphology when stretched inside the electron microscope for strains as high as $40 \%$ (Figure $1 \mathrm{c}, \mathrm{d}$, and Supporting Information (SI), Figure S-1). The appearance of the surface and the pore sizes were obtained for strains exceeding $100 \%$ for this material. ${ }^{14}$ However, in the context of human-machine interfaces, deformable energy storage devices, as well as other applications, the extensibility of electrodes rarely needs to exceed $30 \%$, that is, the limit of skin extensibility in humans. ${ }^{34}$ For this and for practical experimental reasons, we performed electrochemical studies for strains up to $40 \%$.

Cyclic Voltammetry. CV responses of $\mathrm{Au} / \mathrm{PU}$ composite electrodes under $0 \%$ strain and a classical gold foil electrode ( $\mathrm{Au}$ foil) were acquired and compared in the absence and in the presence of $\left[\mathrm{Fe}^{\mathrm{III}}(\mathrm{CN})_{6}\right]^{3-} /\left[\mathrm{Fe}^{\mathrm{II}}(\mathrm{CN})_{6}\right]^{4-}$ in the electrolyte (Figure 2). When phosphate-buffered saline (PBS, $\mathrm{pH} 7.4$ ) was used as electrolyte in the absence of $\left[\mathrm{Fe}^{\mathrm{III}}(\mathrm{CN})_{6}\right]^{3-}$ / $\left[\mathrm{Fe}^{\mathrm{II}}(\mathrm{CN})_{6}\right]^{4-}$, the $\mathrm{CV}$ curve from the Au foil electrode was featureless and approached a rectangular shape, as expected for pure double-layer charging currents (Figure 2, inset). The CV curve acquired from a nanocomposite $\mathrm{Au} / \mathrm{PU}$ electrode under the same conditions exhibited higher currents, which were associated with polarization of the nanocomposite. The magnitude of the current densities in electrolytes that contained solely PBS $\left( \pm 0.04 \mathrm{~mA} / \mathrm{cm}^{2}\right)$ indicated that electrolytic contribution to the redox processes in the presence of $\left[\mathrm{Fe}^{\mathrm{III}}(\mathrm{CN})_{6}\right]^{3-} /\left[\mathrm{Fe}^{\mathrm{II}}(\mathrm{CN})_{6}\right]^{4-}$ is negligible. The CV curves in the presence of $\left[\mathrm{Fe}^{\mathrm{III}}(\mathrm{CN})_{6}\right]^{3-} /\left[\mathrm{Fe}^{\mathrm{II}}(\mathrm{CN})_{6}\right]^{4-}$ in PBS are symmetrical for both $\mathrm{Au}$ foil and $\mathrm{Au} / \mathrm{PU}$ electrodes, as expected for solutions containing identical concentrations of $\mathrm{Fe}^{\mathrm{II}}$ and $\mathrm{Fe}^{\mathrm{III}}$ redox species (Figure 2). The oxidation and

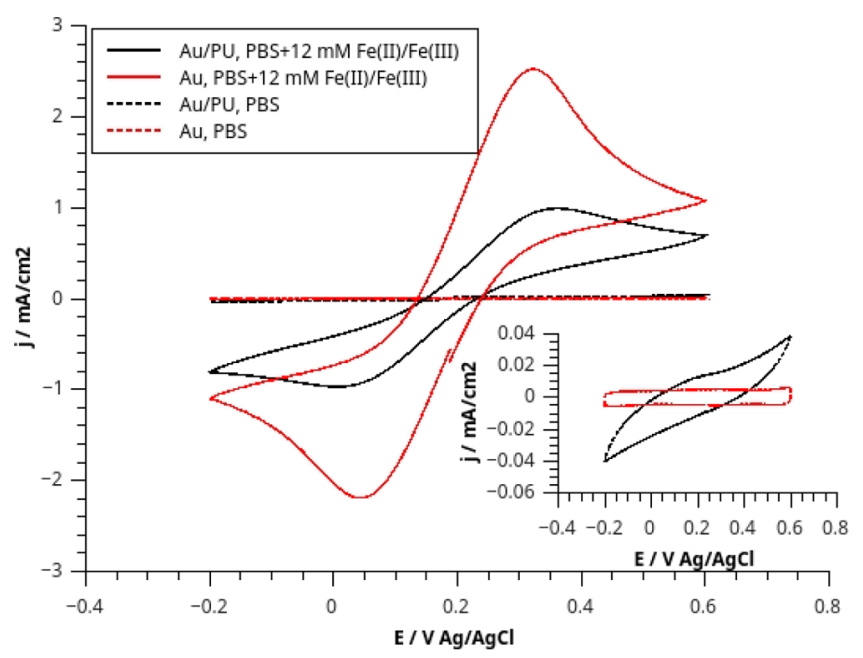

Figure 2. CV curves measured with Au foil (red) and Au/PU composite (black) electrodes with a scan rate of $20 \mathrm{mV} / \mathrm{s}$ in $0.5 \mathrm{M}$ PBS solution without (dashed lines) and in the presence of $12 \mathrm{mM}$ $\left[\mathrm{Fe}^{\mathrm{III}}(\mathrm{CN})_{6}\right]^{3-} /\left[\mathrm{Fe}^{\mathrm{II}}(\mathrm{CN})_{6}\right]^{4-}$ (plain lines). The inset shows a zoom of $\mathrm{CV}$ obtained without the redox probe. The currents are reported as current densities; that is, they refer to the geometric surface area of the corresponding electrode for adequate comparison.

reduction peak separation on the Au foil electrode was $\Delta E_{\mathrm{p}} \approx$ $0.28 \mathrm{~V}$, which demonstrated the quasi-reversible character of the $\left[\mathrm{Fe}^{\mathrm{III}}(\mathrm{CN})_{6}\right]^{3-} /\left[\mathrm{Fe}^{\mathrm{II}}(\mathrm{CN})_{6}\right]^{4-}$ transition on Au foil; this also indicated that the reaction rate is controlled by both iron complex mass transport and reaction kinetics. ${ }^{35}$ Peak separation was larger for the $\mathrm{Au} / \mathrm{PU}$ composite electrodes (Table 1). Assuming that diffusion coefficients of electroactive

Table 1. Parameters of CV Curves Measured with Au Foil and $\mathrm{Au} / \mathrm{PU}$ Electrodes at Different Strains at a Scan Rate of $20 \mathrm{mV} / \mathrm{s}$ in $0.5 \mathrm{M}$ PBS Solution in the Presence of $12 \mathrm{mM}$ $\left[\mathrm{Fe}^{\mathrm{III}}(\mathrm{CN})_{6}\right]^{3-}$ and $\left[\mathrm{Fe}^{\mathrm{II}}(\mathrm{CN})_{6}\right]^{4-}$ Electrolyte

\begin{tabular}{|c|c|c|c|}
\hline electrode & $\begin{array}{l}\text { equilibrium potential, } \\
E_{0}, \mathrm{~V}(\text { vs } \mathrm{Ag} / \mathrm{AgCl})^{a}\end{array}$ & $\begin{array}{c}\text { peak current, } \\
i_{\mathrm{p}, \mathrm{a}} / i_{\mathrm{p}, \mathrm{c}}, \mathrm{mA} \cdot \mathrm{cm}^{-2}\end{array}$ & $\begin{array}{c}\text { peak separation, } \\
\Delta E, \mathrm{~V}\end{array}$ \\
\hline Au foil & 0.18 & $2.5 / 2.2$ & 0.28 \\
\hline $\mathrm{Au} / \mathrm{PU} 0 \%$ & 0.16 & $0.99 / 0.98$ & 0.45 \\
\hline $\mathrm{Au} / \mathrm{PU} 10 \%$ & 0.16 & $1.33 / 1.25$ & 0.47 \\
\hline $\mathrm{Au} / \mathrm{PU} 20 \%$ & 0.15 & $1.42 / 1.33$ & 0.47 \\
\hline $\mathrm{Au} / \mathrm{PU} 30 \%$ & 0.15 & $1.52 / 1.41$ & 0.45 \\
\hline $\mathrm{Au} / \mathrm{PU} 40 \%$ & 0.15 & $1.89 / 1.82$ & 0.32 \\
\hline
\end{tabular}

${ }^{a}$ The values are calculated as a half-position potential between the potentials of cathodic and anodic CV peaks.

species to both the $\mathrm{Au}$ foil and Au/PU are the same (an assumption that is confirmed later in this paper) one can conclude that the redox reaction rate is slower on the $\mathrm{Au} / \mathrm{PU}$ composite than it is on an $\mathrm{Au}$ foil electrode. Peak currents measured for a non-stretched $\mathrm{Au} / \mathrm{PU}$ electrode were about 2.0-2.5 times lower than those of the $\mathrm{Au}$ foil electrode. Between 0 and $40 \%$ of strain, the $\mathrm{Au} / \mathrm{PU}$ nanocomposite electrode in contact with $\mathrm{PBS}$ in the absence of $\left[\mathrm{Fe}^{\mathrm{III}}(\mathrm{CN})_{6}\right]^{3-} /\left[\mathrm{Fe}^{\mathrm{II}}(\mathrm{CN})_{6}\right]^{4-}$ displayed a considerable increase of currents (Figure 3). The capacitance increase with strain could be due to an increase of the active area of the electrode (see section $\mathrm{D}$ ) leading to an increase of the double layer area formed during the application of the potential. This 


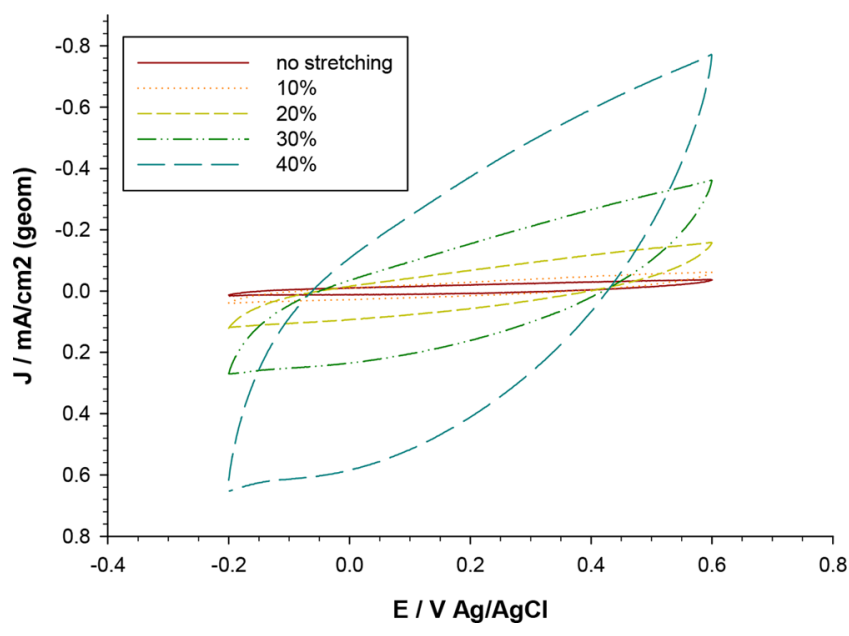

Figure 3. Capacitive current for a Au/PU nanocomposite electrode in contact with PBS for different strains from $0 \%$ to $40 \%$.

double layer is different than the area of a bare gold surface due to the presence of the cationic polyurethane around the AuNPs. In the presence of $12 \mathrm{mM}\left[\mathrm{Fe}^{\mathrm{III}}(\mathrm{CN})_{6}\right]^{3-} /$ $\left[\mathrm{Fe}^{\mathrm{II}}(\mathrm{CN})_{6}\right]^{4-}$ (Figure 4 ), the redox wave corresponding to

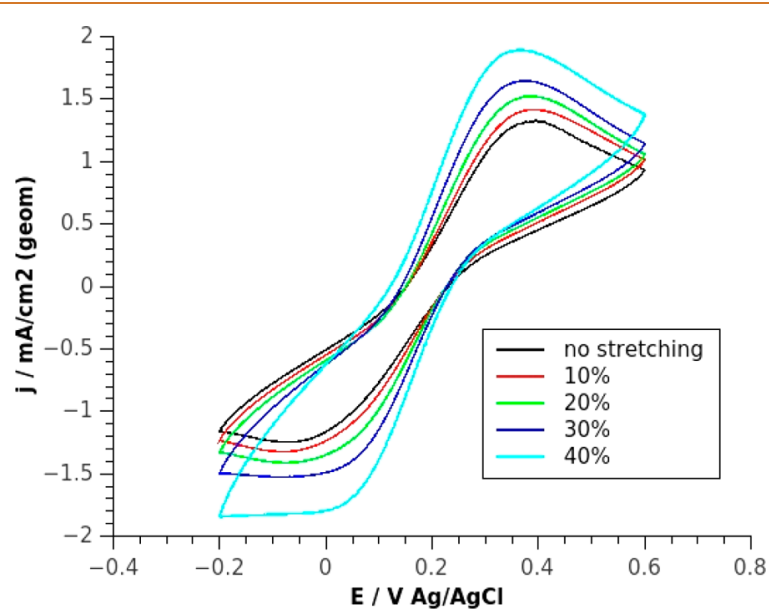

Figure 4. Typical CV curves of $\mathrm{Au} / \mathrm{PU}$ nanocomposite electrodes at different strains $(0,10,20,30$, and $40 \%)$ at a scan rate of 20 $\mathrm{mV} / \mathrm{s}$ in $0.5 \mathrm{M}$ PBS solution in the presence of $12 \mathrm{mM}$ $\left[\mathrm{Fe}^{\mathrm{III}}(\mathrm{CN})_{6}\right]^{3-} /\left[\mathrm{Fe}^{\mathrm{II}}(\mathrm{CN})_{6}\right]^{4-}$.

electron-transfer reactions at the nanocomposite electrolyte interface becomes evident. Importantly, the redox potential is apparently independent of strain for this material within the limits of the tensile deformations tested, that is, $0-40 \%$. Taking into account the capacitive component, the current densities for the $\left[\mathrm{Fe}^{\mathrm{III}}(\mathrm{CN})_{6}\right]^{3-} \rightleftarrows\left[\mathrm{Fe}^{\mathrm{II}}(\mathrm{CN})_{6}\right]^{4-}$ electrontransfer reactions can be estimated. A nearly 2 -fold increase in redox current densities was observed when the strain was increased from $0 \%$ to $40 \%$, which is surprising considering that there was little or no change of surface topography upon stretching within the resolution of these images (Figure 1). Also important, the peak separation decreases with stretching, approaching the value equal to that of a gold foil electrode (Table 1). Both observations can be attributed to an increase of the number of electrochemically active Au NPs due to strain-induced assembly into conductive bands.
Electrochemical Impedance Spectroscopy. Electrochemical Reactions without Strain. Nyquist plots of impedance spectra for the $\mathrm{Au}$ foil electrode and $\mathrm{Au} / \mathrm{PU}$ nanocomposite electrodes were determined under the same conditions as those used for $\mathrm{CV}$, that is, PBS electrolyte with $12 \mathrm{mM}\left[\mathrm{Fe}^{\mathrm{III}}(\mathrm{CN})_{6}\right]^{3-} /\left[\mathrm{Fe}^{\mathrm{II}}(\mathrm{CN})_{6}\right]^{4}$ (Figure 5). The impedance of the $\mathrm{Au}$ foil electrode in this electrolyte (Figure 5a) follows the Randles model (red line) that describes the double-layer charging of a flat electrode/electrolyte interface with a concurrent reversible redox reaction. The latter is controlled by planar diffusion and charge-transfer rate constant specific for the electrode material, and electroactive species. The essential parameters of the Randles model (Figure 5 inset) are $R_{\mathrm{el}}$, the resistance of the electrolyte; $C_{\mathrm{dl}}$, the double-layer capacity due to electrolyte ion adsorption; $R_{\mathrm{ct}}$ the resistance of charge transfer for the redox process; and $W$, the Warburg impedance related to planar diffusion toward the electrode of the redox species. Fitting of the experimental plots by the Randles model allowed us to find the values of the impedance components, which point to the following electrochemical parameters of $\mathrm{Fe}(\mathrm{II}) / \mathrm{Fe}(\mathrm{III})$ redox process for the $\mathrm{Au}$ foil electrode: surface specific capacitance $C_{2}=27 \pm 5 \mu \mathrm{F} / \mathrm{cm}^{2}$, charge-transfer rate constant $k=(1.4 \pm 0.2) \times 10^{-3} \mathrm{~cm} \cdot \mathrm{s}^{-1}$, and diffusion coefficients of $\left[\mathrm{Fe}(\mathrm{CN})_{6}\right]^{3-}$ and $\left[\mathrm{Fe}(\mathrm{CN})_{6}\right]^{4-} \mathrm{D}$ $=(1.5 \pm 0.5) \times 10^{-5} \mathrm{~cm}^{2} \cdot \mathrm{s}^{-1}$ (see eq $\mathrm{S}-1$ in the SI). These results agree with those in the literature. ${ }^{36,37}$

Impedance spectra of $\mathrm{Au} / \mathrm{PU}$ electrodes at $0 \%$ strain (Figure $5 b)$ are qualitatively similar to those found on the $\mathrm{Au}$ foil electrodes (Figure 5a), which agrees with the previous findings of metal-like behavior of these composites. ${ }^{14}$ When fitting the experimental plots with the Randles model one can see significant discrepancies, however. A reasonable agreement can be obtained for the high and intermediate frequency domains whereas deviations from the model are clearly detected at the low-frequency limit (below $0.01 \mathrm{~Hz}$ ): the slope of the impedance plot is lower than the $45^{\circ}$ expected for flat Warburg diffusion impedance. From the EIS data measured at high and moderate frequencies (Randles model applied), the active surface area of $\mathrm{Au}$ in the nanocomposite electrode can be estimated. The semi-circle of the spectra are slightly flattened, and thus the double layer capacitance is better fitted by a constant phase element (CPE) of $a=0.85$. The deviation of the CPE constant, $a$, from 1 (ideal capacitor) is usually related to heterogeneity or micro-roughness of the surface, ${ }^{38}$ which corresponds well to the nanocomposite electrode topography observed by SEM (Figure 1a,b). For a nonstretched $\mathrm{Au} / \mathrm{PU}$ nanocomposite electrode, we found $0.21 \mathrm{~cm}^{2}$ of $\mathrm{Au}$ surface area per $1 \mathrm{~cm}^{2}$, indicating that approximately $20 \%$ of the electrode surface is composed of Au NPs that are redox active. The kinetic parameters of the $\mathrm{Fe}^{\mathrm{II}} / \mathrm{Fe}^{\mathrm{III}}$ reaction on the $\mathrm{Au} / \mathrm{PU}$ composite electrodes were also calculated from a Randles circuit (applied in high and intermediate frequencies $)$ and found to be $k=(0.9 \pm 0.2) \times 10^{-3} \mathrm{~cm} \cdot \mathrm{s}^{-1}$ and $D=(1.10 \pm 0.05) \times 10^{-5} \mathrm{~cm}^{2} \cdot \mathrm{s}^{-1}$. This fact shows that the electrochemical activity or accessibility of the Au of the Au/PU electrode surface is lower compared to Au foil, which should be associated with the presence of PU. The diffusion conditions are, nevertheless, similar for both Au foil and the surface of $\mathrm{Au} / \mathrm{PU}$ nanocomposite, as indicated by the close values of diffusion coefficients, where $D$ for $\mathrm{Au}$ foil is equal to $1.50 \times 10^{-5} \mathrm{~cm}^{2} \cdot \mathrm{s}^{-1}$. The electrochemically active part of the electrode and specifically, the nanoscale particles capable of sustaining the redox reaction will be referred as open surface. 


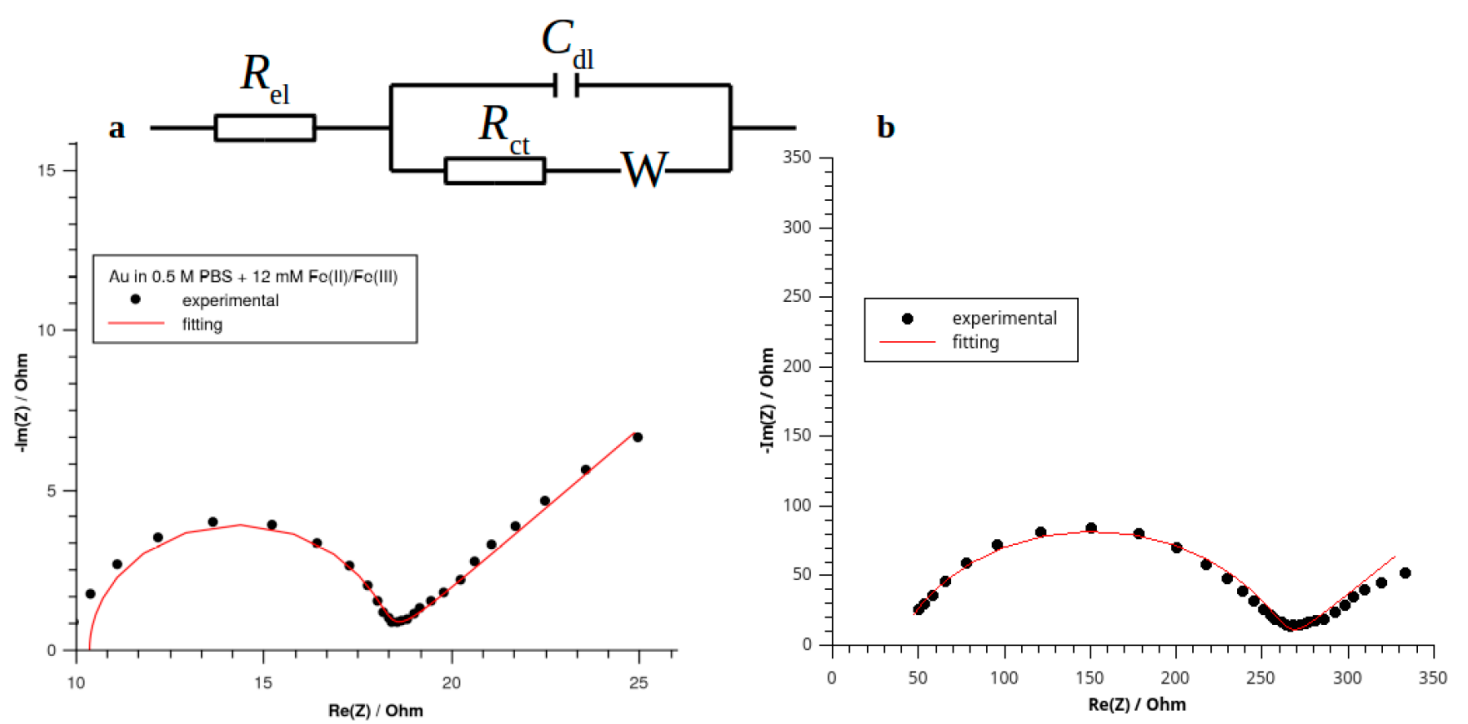

Figure 5. Impedance spectra of (a) Au foil and (b) Au/PU composite electrodes measured at equilibrium potential $E_{0}=0.136 \mathrm{~V}$ (vs $\mathrm{Ag}$ / $\mathrm{AgCl})$ in $0.5 \mathrm{M}$ PBS solution in the presence of $12 \mathrm{mM}\left[\mathrm{Fe}^{\mathrm{III}}(\mathrm{CN})_{6}\right]^{3-} /\left[\mathrm{Fe}^{\mathrm{II}}(\mathrm{CN})_{6}\right]^{4-}$. Inset, Randles model of electrode-electrolyte interface typically used as an equivalent circuit for modeling electrochemically active interfaces.

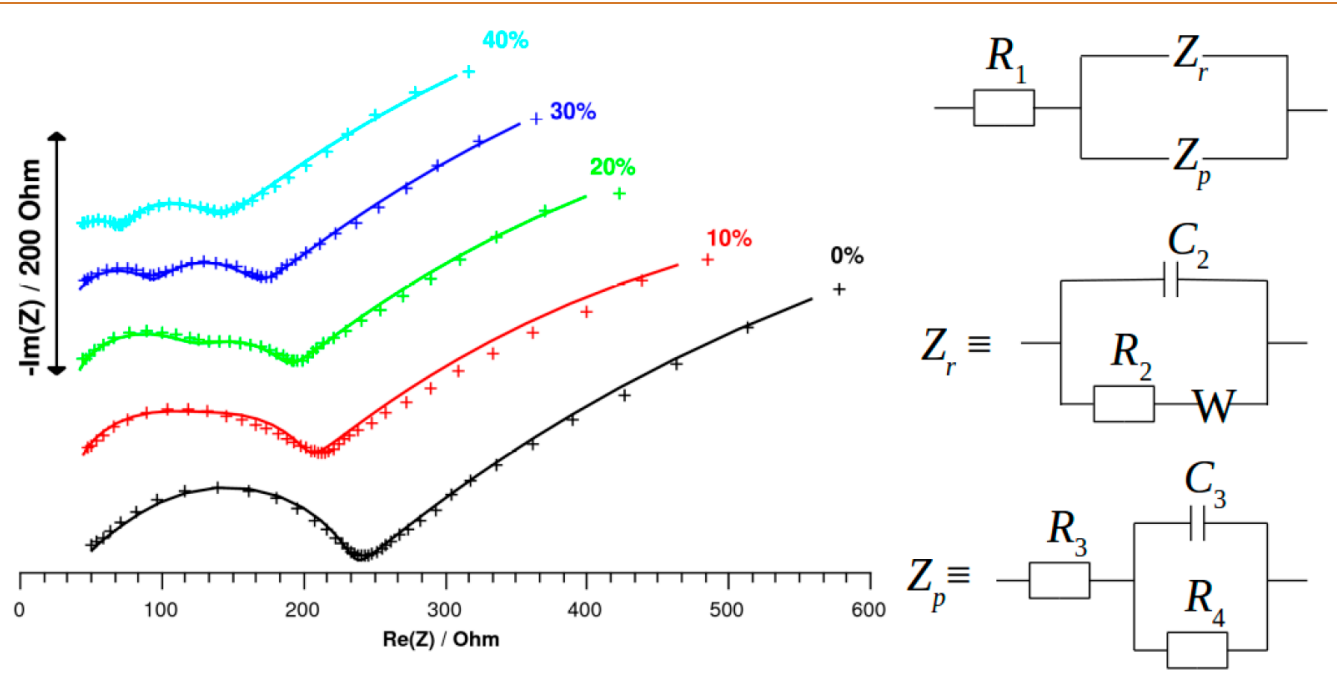

Figure 6. EIS spectra of $\mathrm{Au} / \mathrm{PU}$ electrode, measured at equilibrium potential $E=0.136 \mathrm{~V}(\mathrm{vs} \mathrm{Ag} / \mathrm{AgCl})$ in $0.5 \mathrm{M} \mathrm{PBS}$ solution in the presence of $12 \mathrm{mM}\left[\mathrm{Fe}^{\mathrm{III}}(\mathrm{CN})_{6}\right]^{3-} /\left[\mathrm{Fe}^{\mathrm{II}}(\mathrm{CN})_{6}\right]^{4-}$ at different strains from $0 \%$ to $40 \%$. Inset, schematic representation of the electrochemical model applied on the strain-dependent EIS data obtained with stretchable Au/PU nanocomposite.

The observations of smaller active surface area and lower activity of $\mathrm{Au} / \mathrm{PU} \mathrm{NPs}$ compared to Au foil are in qualitative agreement with lower peak currents of the $\mathrm{CV}$ curves of $\mathrm{Au} /$ PU than those of $\mathrm{Au}$ foil as discussed in the previous section.

Quantitative predictions of the ratio of peak currents on $\mathrm{Au}$ foil and $\mathrm{Au} / \mathrm{PU}$ electrodes are difficult because of the quasireversible character of the $\left[\mathrm{Fe}^{\mathrm{III}}(\mathrm{CN})_{6}\right]^{3-} /\left[\mathrm{Fe}^{\mathrm{II}}(\mathrm{CN})_{6}\right]^{4-}$ redox reaction, that is, its controlled by both mass-transport of $\mathrm{Fe}$ complexes and kinetics of charge transfer. Indeed, in the case of pure mass-transport control (reversible redox reaction) one would expect the same peak currents, as they are referred to a geometric surface area. In the case of pure kinetic control (irreversible redox reaction) one would expect the ratio of peak currents determined by the ratio of Au active surface area and rate constants, that is, peak currents about 7.5 times smaller on $\mathrm{Au} / \mathrm{PU}$ electrodes compared to Au foil. Observed peaks are lower by a factor of $2-2.5$ on $\mathrm{Au} / \mathrm{PU}$ compared to $\mathrm{Au}$ foil, which confirms the quasi-reversible character of the redox processes on the nanocomposite surface.

Thus, $\mathrm{Au} / \mathrm{PU}$ composite electrodes behave under $0 \%$ strain as slightly rough $\mathrm{Au}$ foil electrodes for the $\left[\mathrm{Fe}^{\mathrm{III}}(\mathrm{CN})_{6}\right]^{3-} /$ $\left[\mathrm{Fe}^{\mathrm{II}}(\mathrm{CN})_{6}\right]^{4-}$ transfer reactions, with an active Au surface area that represents approximately $20 \%$ of the total geometric area. The deviation from Nyquist plots of non-stretched $\mathrm{Au} / \mathrm{PU}$ electrodes at low frequencies from the prediction from a Randles model can be attributed to the effect of the porosity of the nanocomposite electrodes. At high and moderate frequencies, the AC modulation signal is probing mostly an open interface while the interface in pores is not active due to a high pore impedance, $Z_{\mathrm{p}}$. The latter is often treated in terms of the DeLevie model, ${ }^{39}$ which takes into account the dependence of depth of penetration of AC signal into pores and predicts that the phase angle, $Z_{\mathrm{p}}$, for semi-infinite pores is half that of the impedance of a flat interface. We shall discuss our 
Table 2. Parameters of Fitting of Experimental EIS Data of Au/PU Electrode at Different Strains in Comparison to Au Foil Obtained for Equivalent Circuit Shown in Figure 5

\begin{tabular}{lccccccc}
\multicolumn{1}{c}{ electrode } & $R_{1}, \Omega$ & $C_{2}, \mu \mathrm{F}$ & $R_{2}, \Omega$ & $W, \Omega \cdot \mathrm{s}^{-1 / 2}$ & $R_{3}, \Omega$ & $C_{3}, \mu \mathrm{F}$ & \\
$\mathrm{Au}$ foil & 10.4 & 51.8 & 7.7 & 5.38 & & & \\
$\mathrm{Au} / \mathrm{PU} \%$ & 41.0 & 1.39 & 357.7 & 148.3 & & & \\
$\mathrm{Au} / \mathrm{PU} 10 \%$ & 40.8 & 2.89 & 186.6 & 70.2 & 251.5 & 5.81 & 891.7 \\
$\mathrm{Au} / \mathrm{PU} \mathrm{20 \%}$ & 39.3 & 3.85 & 165.8 & 52.8 & 206.2 & 19.9 & 979.9 \\
$\mathrm{Au} /$ PU 30\% & 38.6 & 4.77 & 136.8 & 42.8 & 103.4 & 56.9 & 1223 \\
$\mathrm{Au} /$ PU 40\% & 37.4 & 5.62 & 105.0 & 38.2 & 51.6 & 149.8 & 1143
\end{tabular}

Table 3. Electrochemical Parameters Describing the Interface of Au/PU Electrode at Different Strains in Comparison to Au Foil Electrode

\begin{tabular}{|c|c|c|c|c|c|}
\hline \multicolumn{3}{|c|}{$A_{1}, \mathrm{~cm}^{2} / 1 \mathrm{~cm}^{2}$ geom. } & \multicolumn{3}{|c|}{$A_{2}, \mathrm{~cm}^{2} / 1 \mathrm{~cm}^{2}$ geom. } \\
\hline electrode & $\left(A_{1} / A_{1}(0 \%)\right)^{a}$ & $k_{1}, \mathrm{~cm} \cdot \mathrm{s}^{-1}$ & $D, \times 10^{5} \mathrm{~cm}^{2} \cdot \mathrm{s}^{-1}$ & $\left(A_{2} / A_{1}(0 \%)\right)^{a}$ & $k_{2}, \mathrm{~cm} \cdot \mathrm{s}^{-1}$ \\
\hline Au foil & 1.04 & 1.40 & 1.50 & & \\
\hline $\mathrm{Au} / \mathrm{PU} 0 \%$ & $0.20(1)$ & 1.11 & 1.44 & & \\
\hline $\mathrm{Au} / \mathrm{PU} 10 \%$ & $0.36(1.8)$ & 1.02 & 1.49 & $0.68(3.4)$ & 0.107 \\
\hline $\mathrm{Au} / \mathrm{PU} 20 \%$ & $0.41(2.05)$ & 0.87 & 1.49 & $2.19(10.9)$ & 0.028 \\
\hline $\mathrm{Au} / \mathrm{PU} 30 \%$ & $0.48(2.4)$ & 0.85 & 1.47 & $5.74(28.7)$ & 0.008 \\
\hline $\mathrm{Au} / \mathrm{PU} 40 \%$ & $0.52(2.6)$ & 0.94 & 1.33 & $14.03(70.1)$ & 0.003 \\
\hline
\end{tabular}

observations related to the $Z_{\mathrm{p}}$ appearance in more detail below with the results of the stretching of our $\mathrm{Au} / \mathrm{PU}$ electrode.

Electrochemical Reactions under Strain. The strain dependence of the Nyquist plots for $\mathrm{Au} / \mathrm{PU}$ composite (Figure 6) provides a detailed look on the changes of interfacial properties of the interface between $\mathrm{Au} / \mathrm{PU}$ electrodes and electrolyte. As mentioned above, the Randles model cannot completely fit the EIS spectra at low frequencies, which is due to pore impedance. This contribution becomes obvious when the strain reaches $20 \%$ where Nyquist plots acquire the second semi-arc in the intermediate frequency range. This qualitative change can be described by Lasia's model of pore impedance. $^{33}$ This model takes into account frequency dispersion of charge-transfer resistance in the case of porous electrodes due to the formation of a gradient of concentration of redox active species along the length of the pore that, in our case, include nanometer and sub-nanometer scale pores. We shall collectively refer to them as nanopores. According to the Lasia's model, the impedance of porous electrodes depends on the Thiele modulus, $\Phi_{0}$, used in catalysis to evaluate the efficiency of the use of active surfaces in porous catalysts. When $\Phi_{0} \ll 1$ (wide, short pores), an electrode behaves as a flat interface and only one semi-arc is observed. When $\Phi_{0} \gg 1$ (semi-infinite pores), the total impedance is predominantly determined by the impedance of the reaction in the pores, which is frequency-dependent, and again, only one semi-arc is observed. For intermediate values of $\Phi_{0}$, the current density contributions of the pores and at the open interface to the impedance are comparable and two semi-arcs are observed as was confirmed in several experimental studies employing electrodes with defined porosity. ${ }^{40-42} \mathrm{~A}$ switch in impedance behavior occurs when changing from a flat to a non-flat electrode while keeping the nature of the electrode unchanged. This opens a possibly for a systematic investigation of the effect of an electrode's strain on the electrochemical parameters for the composite-electrolyte interface.

In order to account for the second semi-arc while stretching, we developed a model for EIS data represented by an equivalent circuit, shown in Figure 6 inset. It consists of a resistance of bulk electrolyte $R_{1}$ in series with circuit segments composed of two parallel circuits: one accounting for the open rough surface (circuit 2 , impedance $Z_{\mathrm{r}}$ ) and another one accounting for nanopores forming under stretching (circuit 3, impedance $Z_{\mathrm{p}}$ ). $Z_{\mathrm{r}}$ is modeled by the same Randles circuit as it was used for the $\mathrm{Au}$ foil electrode. It contains a double layer capacitance of the nanocomposite $C_{2}$ in parallel with impedance of faradaic reaction containing charge-transfer resistance, $R_{2}$, and diffusion Warburg impedance, $W$. Impedance of nanopores $Z_{\mathrm{p}}$ contains a resistance of an electrolyte in the pores $R_{3}$ in parallel with a connection of a double-layer capacitance of Au NPs in pores $C_{3}$ and a chargetransfer resistance $R_{4}$. This resistance represents the resistance of the Au interface in the nanopores and of the electrolyte. The rationale behind this model is that while stretching, the open rough surface increases in area but other pores not taken into account in the rough open surface appear. Both areas, open surface and nanopores, are then in parallel.

Comparing the EIS data with SEM images (Figure 1), we do not observe significant changes of the nanocomposite electrode morphology by SEM while stretching even if EIS spectra reveal such changes. Therefore, the changes must take place over a smaller length scale or inside the nanopores already present at rest, making them not visible in SEM.

Strain Dependence of Electrochemical Parameters. The model in Figure 6 inset that contains two electrical segments allows for fitting the EIS spectra of Au/PU electrodes across the whole range of applied frequencies and for all values of strain. By fitting the experimental data in Figure 6, one can arrive at the set of strain dependent electrochemical parameters given in Table 2 .

The changes of the serial resistance, $R_{1}$, which is mostly related to the resistance of the bulk electrolyte, are negligible and within the error of fitting. As one expects, $R_{1}$ is strain independent. In contrast, the value of $C_{2}$ increases by a factor of about 2.5 between $0 \%$ and $40 \%$ of strain, indicating an increase in the surface area of the nanocomposite at the interface. By relating the value of $C_{2}$ to the specific surface capacitance of the Au foil electrode as measured previously $\left(C_{s}\right.$ 

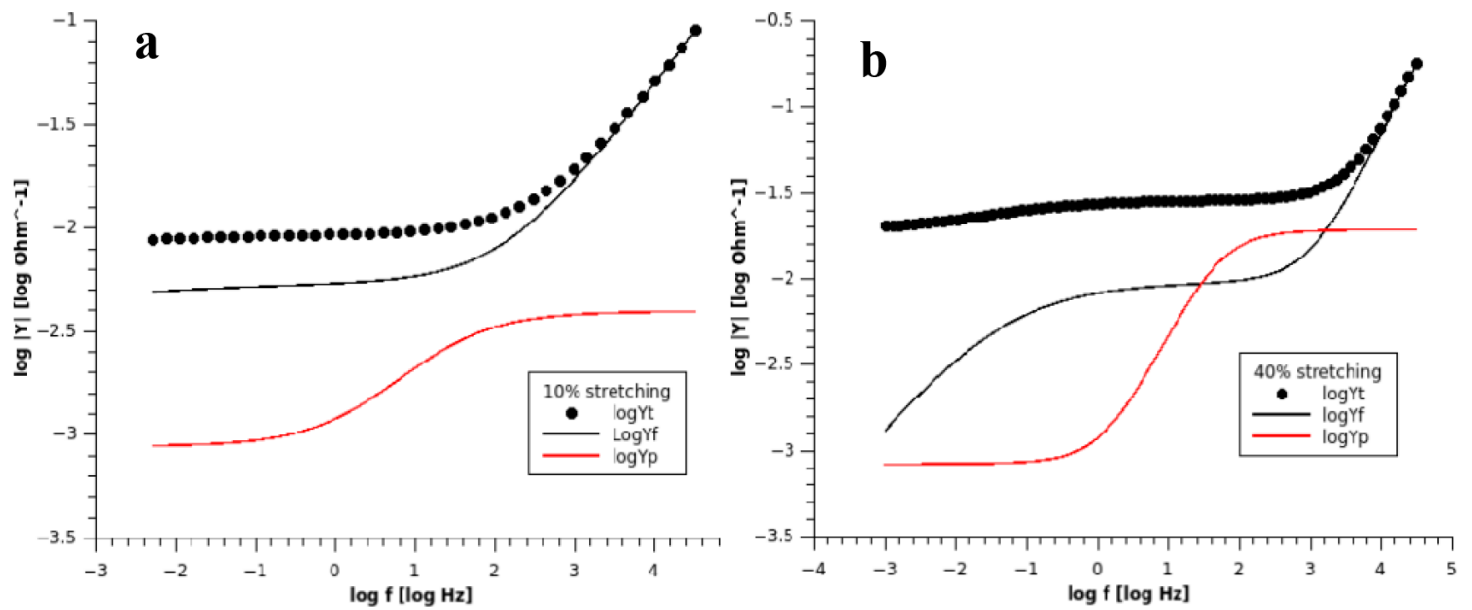

Figure 7. Admittances of $\mathrm{Au} / \mathrm{PU}$ electrodes obtained with strains of (A) $10 \%$ and (B) $40 \%$. Black points represent the total admittance $Y_{t}$, black lines an admittance of an open rough surface $Y_{r}$, and red lines an admittance of pores $Y_{p}$.

$\left.=27 \pm 5 \mu \mathrm{F} / \mathrm{cm}^{2}\right)$, the surface area of $\mathrm{Au} / \mathrm{PU}$ nanocomposites can be estimated at the "open" interface (see $A_{1}$ values in Table 3; for the relations between $R_{2}, W, C_{2}, k_{1}$, and $D$, see eq $S-1$ in the SI). An increase of $A_{1}$ at $40 \%$ of stretching is observed corresponding to 2.5 times the area found in the non-stretched state. This indicates that stretching renders new Au NPs accessible to the electrolyte, which is consistent with the previous observation that NPs in deformable composites for chains under strain thereby making more NPs electroactive. ${ }^{14}$ $R_{2}$ and $W$ are the components of the faradaic impedance, $Z_{\mathrm{r}}$, and are related to the resistance of charge transfer of the redox reaction and to the planar diffusion impedance, respectively. These parameters allow estimation of the heterogeneous rate constant, $k_{1}$, of the electrochemical reaction and the diffusion coefficient, $D$, of $\mathrm{Fe}^{\mathrm{III}}(\mathrm{CN})_{6}^{3-}$ and $\mathrm{Fe}^{\mathrm{II}}(\mathrm{CN})_{6}^{4-}$ complexes in the solution (Table 3 ). We did not detect any significant dependence of $k_{1}$ or $D$ on stretching; both parameters should be therefore considered strain-independent. It shows that neither the interfacial activity nor the mass-transport conditions for conductive nanoscale elements at the interface are changing significantly for different strains; the changes of $Z_{r}$ with stretching are predominantly related to an increase of the exposed surface area. Taking the values of $A_{1}, k_{1}$, and $D$ into account it is possible to calculate the ratio of the $C V$ peak intensities for the different strains. We found that the CV peak intensity at $40 \%$ strain was 2.5 times greater than that at $0 \%$ strain. This matches well with CV data (Figure 4) and validates our model.

We note that although the same model was successfully applied to fit EIS spectra for all strains, we did not use it at $0 \%$ stretching. Indeed, at $0 \%$ strain the uncertainty of the determination of the components of $Z_{\mathrm{p}}$ was too high while a good fit could be obtained without introducing $Z_{\mathrm{p}}$ (Randles model), as discussed previously. Thus, no EIS fitting results for $Z_{\mathrm{p}}$ are given for $0 \%$ strain.

The new model assumes the presence of two types of interfaces at the same time (open surface and nanopores), modeled by two electrical circuits in parallel (Figure 8). In this case, it is more informative to compare their admittances instead of impedances: total admittance, $Y_{t}$, consists of two additive components: admittance of the open surface, $Y_{r}$, and admittance of the pores, $Y_{\mathrm{p}}$, that is, $Y_{\mathrm{t}}=Y_{\mathrm{r}}+Y_{\mathrm{p}}$. Each admittance contributes to a semi-circle in the Nyquist plot of the EIS data. The admittance of nanopores is low at all frequencies and the total admittance is predominantly determined by the admittance of the open interface at $10 \%$ strain (Figure 7a). This means that the electrochemical response is predominantly determined by assemblies of $\mathrm{Au}$ NPs at the open surface. The contributions of the nanopores, however, change with stretching as illustrated by the Bode admittance plot at $40 \%$ strain (Figure $7 \mathrm{~b}$ ). At high frequencies, the admittance of open surface predominates, while admittance of nanopores is limited by the high resistance of the electrolyte in these tight channels, $R_{3}$. Thus, at high frequencies, the total system behaves as an open surface system and a high-frequency semi-arc appears in the Nyquist plots (Figure 6). At intermediate frequencies, the admittance of the open surface particles is limited by the double-layer capacity, $C_{2}$, which decreases rapidly with frequency, and the admittance of nanopores becomes predominant. This is due to the fact that the double-layer capacity of $\mathrm{Au}$ NPs in the nanopores, $C_{3}$, is much higher than $C_{2}$ (Table 2), indicating greater numbers of NPs are in the pores compared to the open surface. On Nyquist plots, a second semi-arc is detected at these frequencies (i.e., between 10 and $1000 \mathrm{~Hz}$ ), which is related to specific nanopore response. The estimation of the surface area of conductive elements from self-assembled Au NPs in the nanopores $\left(A_{2}\right)$ indicates that at $10 \%$ of strain the availability of surface area of $\mathrm{Au}$ in the nanopores is doubled, and is $\sim 27 \%$ greater at $40 \%$ strain. As frequency decreases further, $Y_{\mathrm{p}}$ starts to decrease again due to the frequency dependence of the contribution of $C_{3}$. Thus, at a certain frequency, a contribution of the open surface admittance, $Y_{r}$, becomes predominant again. At these low frequencies, admittance of the open surface is mostly determined by admittance of redox processes (i.e. by $R_{2}$ and $W$ ), which also show up in a nearly Warburg-like Nyquist plot segment. Finally, at low frequencies the admittance of nanopores is limited by the resistance of electrolyte, $R_{3}$, and the interfacial resistance, $R_{4}$, the latter of which is relatively high. This indicates that the redox reaction on the surface of the self-assembled conductive elements from NPs in nanopores is significantly slowed down compared to the reaction at the open surface. This fact is reflected by the small values of the rate constant $k_{2}$ (Table 3 ) compared to $k_{1}$, which can be rationalized either via significantly lower concentrations of $\left[\mathrm{Fe}^{\mathrm{III}}(\mathrm{CN})_{6}\right]^{3-}$ and $\left[\mathrm{Fe}^{\mathrm{II}}(\mathrm{CN})_{6}\right]^{4-}$ in the 
nanopores or by blocking of the NP surface by PU. Because the open surface admittance decreases with frequency, the contribution of the nanopore admittance becomes increasingly significant at low frequencies, which is observed as a deviation from straight Warburg impedance on the Nyquist plots.

The use of EIS to illustrate the strain dependence of the $\mathrm{Au} /$ PU electrode revealed a systematic increase of the total surface area of exposed $\mathrm{Au}$ NPs with increased strain. At low strain ( $0 \%$ and $10 \%)$ the electrochemical properties of the electrode are dominated by the conducting elements from Au NPs located at the open surface, whose population increases roughly by factor 2.5 when the electrode is stretched to $40 \%$. The interfacial properties of these particles are not changing significantly: neither their activity in the redox reaction nor the mass-transport conditions toward the interface change with strain. These are the NPs that are involved in the redox reaction at the electrode. At the same time, with stretching, a new contribution, not predicted by SEM, of Au NPs in the nanopores appears and becomes more and more significant with stretching at intermediate frequencies. These NPs contribute significantly to the double layer capacitance, but for the redox reaction between $\left[\mathrm{Fe}^{\mathrm{III}}(\mathrm{CN})_{6}\right]^{3-}$ and $\left[\mathrm{Fe}^{\mathrm{II}}(\mathrm{CN})_{6}\right]^{4-}$ their contribution is negligible. The significance of the strain-dependence of these parameters highlighted by the fact that the surface area of NPs in the stretched electrode is of the order of 27 times greater than that of the open rough surface area of the initial non-stretched state. The considerable increase of the electroactive area of the nanopores can be associated with the incorporation of the previously electrochemically inactive NPs into the conductive network due to the reversible strain-induced self-organization of the NPs into bands. ${ }^{14}$ Also, the reorganization of the composite material is likely to change the conformation of the polymeric chains on the surface of gold NPs potentially allowing penetration of larger number of ions to gold surface in under strain than in relaxed state.

The tests of reversibility of electrochemical behavior of $\mathrm{Au} /$ PU electrodes by measuring their impedance after decreasing the strain from $40 \%$ back to $20 \%$. Qualitatively similar Nyquist diagrams were observed at $20 \%$ strain before and after the stretching to $40 \%$ (Figure S-2, SI). Also the values of $\mathrm{Au}$ specific surface area $A_{1}$ (open surface) and $A_{2}$ (particles in pores) change quasi-reversibly with strain (Table S-1, SI). Besides slow relaxation kinetics in the nanocomposites, the differences in $A_{1}$ and $A_{2}$ values at $20 \%$ before and after stretching to $40 \%$ is an indication of a plastic deformation in the composite as was observed before. ${ }^{14}$ The change of the direction of the strain can result in the further structural reorganization.

\section{CONCLUSIONS}

Nanoparticle composites with self-organizing conducting pathways opened the possibility to systematically vary strain while retaining the chemical composition and surface topography of stretchable electrodes. It enabled us to address the questions of the strain dependence of key electrochemical parameters for deformable electrodes and elaboration of a strain-dependent circuit model for deformable electrodes. We found that the redox potentials of $\left[\mathrm{Fe}^{\mathrm{III}}(\mathrm{CN})_{6}\right]^{3-}$ and $\left[\mathrm{Fe}^{\mathrm{II}}(\mathrm{CN})_{6}\right]^{4-}$ pair are strain-independent for the window of tensile strains from $0 \%$ to $40 \%$. The electrochemical behavior of the nanocomposite electrode in the relaxed state can be described well by the classic Randles model, but the strained composite cannot. Instead, an electrochemical model with two parallel circuits and strain-dependent electrochemical parameters must be applied. One impedance segment in the developed model corresponds to a diffusion/reaction process at an open rough surface, whereas another one corresponds to electrochemical processes taking place in (sub)nanometerscale pores that may not be distinguishable on electron microscopy images. By stretching the electrode, the area corresponding to the open surface circuit increases by a factor of 2.5 for a $40 \%$ strain, whereas the area of the nanopore circuit is 27 times that of the initial area of the electrode in the nonstretched state. Only the Au NPs corresponding to the open surface circuit participate in the electrochemical reaction, whereas those of the nanopore circuit contribute only to the double-layer capacitance. The dramatic increase of the electroactive area is attributed to the increase of number of NPs self-assembling into the conductive network under strain and interfacial reorganization of PU chains. Conceptually similar deformation-induced phase-separation processes can also be observed in nanocarbon composites, ${ }^{43,44}$ and therefore a similar strain-dependent electrochemical phenomenon should be expected for them as well. This study opens the route to engineering of materials for biomimetic electrodes, implantable electronics, and deformable charge storage devices based on stretchable nanocomposites, by providing an accurate account of the charge-transport processes at the interfaces.

\section{MATERIALS AND METHODS}

Materials. Potassium hexacyanoferrate(II) trihydrate and potassium hexacyanoferrate(III) were purchased by Merck (Darmstadt, Germany). Gold(III) chloride trihydrate, sodium citrate tribasic dihydrate, and phosphate-buffered saline (PBS) tablets were purchased from VWR (Radnor, Pennsylvania, USA). Cationic polyurethane aqueous dispersion (30 vol\%, molecular mass approximately 92000) was purchased by Hepce Chem (South Korea). All chemicals were used as received.

Synthesis of Gold Nanoparticles (AuNPs). Gold(III) chloride trihydrate $(180.0 \mathrm{mg}, 0.458 \mathrm{mmol})$ was added to ultrapure deionized water $(950 \mathrm{~mL})$ in a $1 \mathrm{~L}$ glass beaker equipped with a magnetic stir bar. The mixture was heated to boiling under vigorous stirring followed by additional heating for $20 \mathrm{~min}$. Subsequently, $50 \mathrm{~mL}$ of 34 $\mathrm{mM}$ sodium citrate solution was added to the mixture. The aqueous solution was heated for $20 \mathrm{~min}$ followed by cooling to room temperature. Citrate-stabilized AuNPs with diameter $13.6 \pm 0.3 \mathrm{~nm}$ were synthesized. The as-prepared aqueous solution was directly used for the preparation of VAF films.

Preparation of Vacuum-Assisted Flocculation Films. To a glass beaker containing $1 \mathrm{~L}$ of as-prepared AuNPs dispersion (no additional concentration steps were applied) equipped with a magnetic stir bar, we slowly added $1 \mathrm{~mL}$ of 1.0 vol\% aqueous polyurethane. The mixture was stirred for $15 \mathrm{~min}$ followed by filtration. Filter papers of $0.8-\mu \mathrm{m}$ pore size with $47 \mathrm{~mm}$ diameter, and the filtration assembly, were obtained from Fisher Scientific. The resultant gold-colored film was peeled off the filter paper. We recommend drying the film completely before taking it out from the filtration assembly. Individual peeled-off films have some fibrous material attached that comes from the filter paper, which can be removed by gentle scratching. Conditions and procedures for the preparation of VAF films with various gold contents were the same except for the volumetric ratios of the dispersion of as-prepared AuNP solutions. VAF films with high conductivity were prepared from 650 $\mathrm{mL}$ of as-prepared AuNP dispersion, respectively. To make a $30 \mu \mathrm{m}$ thick VAF film, in total about $1800 \mathrm{~mL}$ of solution needs to be filtered.

Electrochemical Measurements. Electrochemical measurements were performed in a three-electrode cell, which consisted of a beaker with three inserted electrodes. Pt-coiled wire served as a 
counter electrode $(\mathrm{CE})$, and a $\mathrm{Ag} / \mathrm{AgCl}$ electrode was used as a reference electrode (RE). The working electrode (WE) was a Au/PU composite electrode cut with a size of $2 \mathrm{~mm} \times 20 \mathrm{~mm}$. The electrolyte in the cell was purged with $\mathrm{N}_{2}$ for $15 \mathrm{~min}$ before each measurement to avoid the currents related to $\mathrm{O}_{2}$ reduction. The entire cell setup was placed into a closed gas reservoir filled with $\mathrm{N}_{2}$ in order to protect it from air. A constant flow of $\mathrm{N}_{2}$ was kept in the chamber during the experiment. CV was performed using a $\mathrm{CHI} 660 \mathrm{E}$ Electrochemical Workstation ( $\mathrm{CH}$ Instrument, USA). Impedance measurements were performed using a SP-300 Bio-Logic potentiostat (Grenoble, France), equipped with an impedance module. Impedance measurements were conducted at equilibrium potential by the application of $7 \mathrm{mV}$ AC amplitude and a frequency range from 100 $\mathrm{kHz}$ to $0.01 \mathrm{~Hz}$. The analysis of impedance data was accomplished with EC-Lab Bio-Logic software (Zfit module). Phosphate buffer solution was prepared using PBS tablets, $0.5 \mathrm{M}$ phosphate buffer, 6.85 $\mathrm{M} \mathrm{NaCl}$, and $0.135 \mathrm{M} \mathrm{KCl}$ and adjusted at $\mathrm{pH}$ 7.4. One should note that the absolute values of parameters like the areas $A_{1}$ and $A_{2}$, the areas introduced in our model, may be quite different from one sample to the other for $\mathrm{Au} / \mathrm{PU}$ composite but similar trends as far as variations of these parameters with strain are concerned. This variability is attributed to the variability of the commercial PU material. We observed that both mechanical and electrical properties of our composite films were batch-dependent.

Scanning Electron Microscopy. SEM assessments were performed using a Quanta 250 ESEM (FEI Company, Eindhoven, The Netherlands) operating with an accelerating voltage of $10 \mathrm{kV}$. To obtain the images under stretching, we used a custom-made stretching device that was introduced into the microscope.

Stretching Device. We designed a custom-made stretching device to perform the electrochemical experiments (Figure S-3, SI). Au/PU composite electrodes were attached between two clamps on a stretching platform. The platform was made of non-metallic materials and immersed in a beaker containing the electrolyte solution. A small part of the $\mathrm{Au} / \mathrm{PU}$ composite electrode was out of the electrolyte, in order to make the electrical connection to the potentiostat. All measurements presented here are expressed in current density depending on the length of immersed nanocomposite electrode measured with a caliper. The platform was connected to a motorized axis that allowed movement of one of the clamps, and therefore induced a stretching of the attached membrane, at a speed of 0.012 $\mathrm{mm} / \mathrm{s}$. The first electrochemical measurement was performed at $0 \%$ strain. Then the nanocomposite electrode was stretched to $10 \%$ of its initial length, with 5 min relaxation before each measurement, until the strain reached $40 \%$.

Conductivity Measurements. Conductivity measurements with four-probe methods were obtained using a 34401A digital multimeter, $61 / 2$ Digit (Agilent Technologies, USA). The four probes were placed on the sample. Change of resistance on the multimeter and change of strain on the display of tensile machine were video recorded together. Sample being stretched was photographed to see change of length and width (one photograph was taken every second) to calculate thickness of sample at each photograph. Video recorded resistance, strain, and thickness data were used to calculate data points for the conductivity values as a function of strain. Tensile measurements were performed by testing $\sim 1 \mathrm{~mm}$ wide and 5-7 $\mathrm{mm}$ long rectangular strips of samples with a mechanical strength tester $100 \mathrm{Q}$ (Test Resources, USA). Tests were performed at a rate of $0.08 \mathrm{~mm} \mathrm{~s}^{-1}$ for laminated VAF films with a $\sim 111 \mathrm{~N}$ range load cell. The conductivity of the different membranes was typically of the order of $900 \mathrm{~S} / \mathrm{cm}$ at $0 \%$ strain and decreases with strain as shown in Figure S-4 (SI). This leads to resistances of the electrodes at rest of the order of $1 \Omega$ taking into account the dimensions of the electrodes.

\section{ASSOCIATED CONTENT}

\section{(5 Supporting Information}

The Supporting Information is available free of charge on the ACS Publications website at DOI: 10.1021/acsnano.8b03962.
Equations of the impedance of a Randles circuit; equations of the model of $\mathrm{Au} / \mathrm{PU}$ electrode; SEM images of a composite $\mathrm{Au} / \mathrm{PU}$ electrode at different strains; picture of the homemade stretching device used for electrochemical experiments; EIS spectra and table of reversibility test of $\mathrm{Au} / \mathrm{PU}$ electrodes under strain; conductivity of $\mathrm{Au} / \mathrm{PU}$ electrodes (PDF)

\section{AUTHOR INFORMATION}

\section{Corresponding Authors}

*E-mail: fouzia.boulmedais@ics-cnrs.unistra.fr.

*E-mail: schaaf@unistra.fr.

*E-mail: kotov@umich.edu.

ORCID

Fouzia Boulmedais: 0000-0002-4934-9276

Pierre Schaaf: 0000-0001-7423-5492

Nicholas A. Kotov: 0000-0002-6864-5804

\section{Notes}

The authors declare no competing financial interest.

\section{ACKNOWLEDGMENTS}

L.L. was supported by a fellowship from the "Ministère de la Recherche et de la Technologie". The authors gratefully acknowledge financial support from Agence Nationale de la Recherche (ANR MECHANOCAT, ANR-15-CE29-0015). Y.K. and N.A.K. were supported by the NSF projects "Energyand Cost-Efficient Manufacturing Employing Nanoparticles" (NSF 1463474), "Nanospiked Particles for Photocatalysis" (NSF 1566460); "Layered Composites from Branched Nanofibers for Lithium Ion Batteries” (NSF 1538180); by MURI, Department of Army, "Reconfigurable Matter from Programmable Colloids" (W911NF-10-1-0518); and by AFOSR, UM 088163, "Nanocomposite Ion Conductors for Thin Film Batteries” (FA9550-16-1-0265).

\section{REFERENCES}

(1) McCreery, R. L. Advanced Carbon Electrode Materials for Molecular Electrochemistry. Chem. Rev. 2008, 108, 2646-2687.

(2) Feeney, R.; Kounaves, S. P. Microfabricated Ultramicroelectrode Arrays: Developments, Advances, and Applications in Environmental Analysis. Electroanalysis 2000, 12, 677-684.

(3) Zhao, S. F.; Li, J. H.; Cao, D. X.; Zhang, G. P.; Li, J.; Li, K.; Yang, Y.; Wang, W.; Jin, Y. F.; Sun, R.; Wong, C. P. Recent Advancements in Flexible and Stretchable Electrodes for Electromechanical Sensors: Strategies, Materials, and Features. ACS Appl. Mater. Interfaces 2017 9, 12147-12164.

(4) Zhou, A.; Sim, R.; Luo, Y. W.; Gao, X. High-Performance Stretchable Electrodes Prepared from Elastomeric Current Collectors and Binders. J. Mater. Chem. A 2017, 5, 21550-21559.

(5) Song, J. H.; Kim, Y. T.; Cho, S.; Song, W. J.; Moon, S.; Park, C. G.; Park, S.; Myoung, J. M.; Jeong, U. Surface-Embedded Stretchable Electrodes by Direct Printing and Their Uses to Fabricate Ultrathin Vibration Sensors and Circuits for 3d Structures. Adv. Mater. 2017, $29,1702625$.

(6) Park, M.; Im, J.; Shin, M.; Min, Y.; Park, J.; Cho, H.; Park, S.; Shim, M. B.; Jeon, S.; Chung, D. Y.; Bae, J.; Park, J.; Jeong, U.; Kim, K. Highly Stretchable Electric Circuits from a Composite Material of Silver Nanoparticles and Elastomeric Fibres. Nat. Nanotechnol. 2012, 7, 803-809.

(7) Rogers, J. A.; Someya, T.; Huang, Y. G. Materials and Mechanics for Stretchable Electronics. Science 2010, 327, 1603-1607.

(8) Suo, Z. G. Mechanics of Stretchable Electronics and Soft Machines. MRS Bull. 2012, 37, 218-225. 
(9) Ramuz, M.; Tee, B. C. K.; Tok, J. B. H.; Bao, Z. N. Transparent, Optical, Pressure-Sensitive Artificial Skin for Large-Area Stretchable Electronics. Adv. Mater. 2012, 24, 3223-3227.

(10) Wang, X. F.; Lu, X. H.; Liu, B.; Chen, D.; Tong, Y. X.; Shen, G. Z. Flexible Energy-Storage Devices: Design Consideration and Recent Progress. Adv. Mater. 2014, 26, 4763-4782.

(11) Rosset, S.; Shea, H. R. Flexible and Stretchable Electrodes for Dielectric Elastomer Actuators. Appl. Phys. A: Mater. Sci. Process. 2013, 110, 281-307.

(12) Lee, M. S.; Lee, K.; Kim, S. Y.; Lee, H.; Park, J.; Choi, K. H.; Kim, H. K.; Kim, D. G.; Lee, D. Y.; Nam, S.; Park, J. U. HighPerformance, Transparent, and Stretchable Electrodes Using Graphene-Metal Nanowire Hybrid Structures. Nano Lett. 2013, 13, 2814-2821.

(13) Urdaneta, M. G.; Delille, R.; Smela, E. Stretchable Electrodes with High Conductivity and Photo-Patternability. Adv. Mater. 2007, 19, 2629-2633.

(14) Kim, Y.; Zhu, J.; Yeom, B.; Di Prima, M.; Su, X. L.; Kim, J. G.; Yoo, S. J.; Uher, C.; Kotov, N. A. Stretchable Nanoparticle Conductors with Self-Organized Conductive Pathways. Nature 2013, 500, 59-63.

(15) Lu, N. S.; Lu, C.; Yang, S. X.; Rogers, J. Highly Sensitive SkinMountable Strain Gauges Based Entirely on Elastomers. Adv. Funct. Mater. 2012, 22, 4044-4050.

(16) Luo, S. D.; Liu, T. Swcnt/Graphite Nanoplatelet Hybrid Thin Films for Self-Temperature- Compensated, Highly Sensitive, and Extensible Piezoresistive Sensors. Adv. Mater. 2013, 25, 5650-5657.

(17) Ma, C. G.; Xi, D. Y.; Liu, M. Epoxy Resin/Polyetherimide/ Carbon Black Conductive Polymer Composites with a Double Percolation Structure by Reaction-Induced Phase Separation. J. Compos. Mater. 2013, 47, 1153-1160.

(18) Chortos, A.; Lim, J.; To, J. W. F.; Vosgueritchian, M.; Dusseault, T. J.; Kim, T. H.; Hwang, S.; Bao, Z. A. Highly Stretchable Transistors Using a Microcracked Organic Semiconductor. Adv. Mater. 2014, 26, 4253-4259.

(19) Feng, J.; Athanassiou, A.; Bonaccorso, F.; Fragouli, D. Enhanced Electrical Conductivity of Poly(Methyl Methacrylate) Filled with Graphene and in Situ Synthesized Gold Nanoparticles. Nano Futures 2018, 2, 025003.

(20) Vural, M.; Behrens, A. M.; Ayyub, O. B.; Ayoub, J. J.; Kofinas, P. Sprayable Elastic Conductors Based on Block Copolymer Silver Nanoparticle Composites. ACS Nano 2015, 9, 336-344.

(21) Farcau, C.; Sangeetha, N. M.; Moreira, H.; Viallet, B.; Grisolia, J.; Ciuculescu-Pradines, D.; Ressier, L. High-Sensitivity Strain Gauge Based on a Single Wire of Gold Nanoparticles Fabricated by Stopand-Go Convective Self-Assembly. ACS Nano 2011, 5, 7137-7143.

(22) Steiner, A. M.; Mayer, M.; Seuss, M.; Nikolov, S.; Harris, K. D.; Alexeev, A.; Kuttner, C.; Konig, T. A. F.; Fery, A. Macroscopic StrainInduced Transition from Quasi-Infinite Gold Nanoparticle Chains to Defined Plasmonic Oligomers. ACS Nano 2017, 11, 8871-8880.

(23) Perez-Juste, J.; Rodriguez-Gonzalez, B.; Mulvaney, P.; LizMarzan, L. M. Optical Control and Patterning of Gold-NanorodPoly(Vinyl Alcohol) Nanocomposite Films. Adv. Funct. Mater. 2005, $15,1065-1071$.

(24) Cheng, T.; Zhang, Y. Z.; Lai, W. Y.; Huang, W. Stretchable Thin-Film Electrodes for Flexible Electronics with High Deformability and Stretchability. Adv. Mater. 2015, 27, 3349-3376.

(25) Baechler, C.; Gardin, S.; Abuhimd, H.; Kovacs, G. Inkjet Printed Multiwall Carbon Nanotube Electrodes for Dielectric Elastomer Actuators. Smart Mater. Struct. 2016, 25, 055009.

(26) Kim, T.; Song, H.; Ha, J.; Kim, S.; Kim, D.; Chung, S.; Lee, J.; Hong, Y. Inkjet-Printed Stretchable Single-Walled Carbon Nanotube Electrodes with Excellent Mechanical Properties. Appl. Phys. Lett. 2014, 104, 113103.

(27) Yuan, W.; Hu, L. B.; Yu, Z. B.; Lam, T. L.; Biggs, J.; Ha, S. M.; Xi, D. J.; Chen, B.; Senesky, M. K.; Gruner, G.; Pei, Q. B. FaultTolerant Dielectric Elastomer Actuators Using Single-Walled Carbon Nanotube Electrodes. Adv. Mater. 2008, 20, 621-625.
(28) Wang, T.; Wang, R. R.; Cheng, Y.; Sun, J. Quasi in Situ Polymerization to Fabricate Copper Nanowire-Based Stretchable Conductor and Its Applications. ACS Appl. Mater. Interfaces 2016, 8, 9297-9304.

(29) Nilchian, A.; Li, C. Z. Mechanical and Electrochemical Characterization of Cnt/Pdms Composited Soft and Stretchable Electrodes Fabricated by an Efficient Solution-Based Fabrication Method. J. Electroanal. Chem. 2016, 781, 166-173.

(30) Kim, B. C.; Jeong, H. T.; Higgins, M. J.; Yu, K. H.; Wallace, G. G. Dynamic Electrochemical Properties of Extremely Stretchable Electrochemical Capacitor Using Reduced Graphene Oxide/SingleWall Carbon Nanotubes Composite. J. Electrochem. Soc. 2015, 162, A2351-A2355.

(31) Jeong, H. T.; Kim, B. C.; Gorkin, R.; Higgins, M. J.; Wallace, G. G. Capacitive Behavior of Latex/Single-Wall Carbon Nanotube Stretchable Electrodes. Electrochim. Electrochim. Acta 2014, 137, 372-380.

(32) Li, X.; Rong, J. P.; Wei, B. Q. Electrochemical Behavior of Single-Walled Carbon Nanotube Supercapacitors under Compressive Stress. ACS Nano 2010, 4, 6039-6049.

(33) Lasia, A. Nature of the Two Semi-Circles Observed on the Complex Plane Plots on Porous Electrodes in the Presence of a Concentration Gradient. J. Electroanal. Chem. 2001, 500, 30-35.

(34) Sugihara, T.; Ohura, T.; Homma, K.; Igawa, H. H. The Extensibility in Human Skin - Variation According to Age and Site. Br. J. Plast. Surg. 1991, 44, 418-422.

(35) Bard, A. J.; Faulkner, L. R. Electrochemical Methods Fundamentals and Applications; John Wiley \& Sons, Inc., New York, 2001.

(36) Marecek, V.; Samec, Z.; Weber, J. The Dependence of the Electrochemical Charge-Transfer Coefficient on the Electrode Potential. J. Electroanal. Chem. Interfacial Electrochem. 1978, 94, 169-185.

(37) Angell, D. H.; Dickinson, T. The Kinetics of the Ferrous/Ferric and Ferro/Ferricyanide Reactions at Platinum and Gold Electrodes. J. Electroanal. Chem. Interfacial Electrochem. 1972, 35, 55-72.

(38) Pajkossy, T. Impedance of Rough Capacitive Electrodes. J. Electroanal. Chem. 1994, 364, 111-125.

(39) Delevie, R. On the Impedance of Electrodes with Rough Interfaces. J. Electroanal. Chem. Interfacial Electrochem. 1989, 261, 1-

(40) Jurczakowski, R.; Hitz, C.; Lasia, A. Impedance of Porous Gold Electrodes in the Presence of Electroactive Species. J. Electroanal. Chem. 2005, 582, 85-96.

(41) Barcia, O. E.; D’Elia, E.; Frateur, I.; Mattos, O. R.; Pebere, N.; Tribollet, B. Application of the Impedance Model of De Levie for the Characterization of Porous Electrodes. Electrochim. Acta 2002, 47, 2109-2116.

(42) Losiewicz, B.; Budniok, A.; Rowinski, E.; Lagiewka, E.; Lasia, A. The Structure, Morphology and Electrochemical Impedance Study of the Hydrogen Evolution Reaction on the Modified Nickel Electrodes. Int. J. Hydrogen Energy 2004, 29, 145-157.

(43) Downes, R.; Wang, S. K.; Haldane, D.; Moench, A.; Liang, R. Strain-Induced Alignment Mechanisms of Carbon Nanotube Networks. Adv. Eng. Mater. 2015, 17, 349-358.

(44) Li, Y. J.; Shimizu, H. Toward a Stretchable, Elastic, and Electrically Conductive Nanocomposite: Morphology and Properties of Poly Styrene-B-(Ethylene-Co-Butylene)-B-Styrene /Multiwalled Carbon Nanotube Composites Fabricated by High-Shear Processing. Macromolecules 2009, 42, 2587-2593. 